\title{
The outcome of primary brachial plexus reconstruction in extended Erb's obstetric palsy when only one root is available for intraplexus neurotization
}

\author{
Mohammad M. Al-Qattan ${ }^{1}$ - Amel Ahmed F. El-Sayed ${ }^{2}$
}

Received: 6 January 2017 / Accepted: 14 March 2017 / Published online: 30 March 2017

(C) The Author(s) 2017. This article is an open access publication

\begin{abstract}
Background A recent review by the International Federation of Societies for Surgery of the Hand showed no studies comparing the results of nerve grafting to distal nerve transfer for primary reconstruction of the brachial plexus in infants with obstetric brachial plexus palsy (OBBP). The aim of this retrospective study is to compare two surgical reconstructive strategies in primary reconstruction of the brachial plexus in extended Erb's obstetric palsy with double root avulsion: one with and one without distal nerve transfer for elbow flexion. Methods Two groups of infants with extended Erb's palsy and double root avulsion were included in the study. Group I $(n=29)$ underwent reconstruction of the brachial plexus without distal nerve transfer. In group II $(n=26)$, the reconstruction included a distal nerve transfer for elbow flexion.

Results Both groups had an excellent (over 96\%) satisfactory outcome for elbow flexion. Group II has a significantly better outcome $(P<0.05)$ of shoulder abduction and wrist extension than group I.

Conclusions The use of a distant nerve transfer for bicep reconstruction in extended Erb's obstetric palsy with double root avulsion gives a better outcome for shoulder abduction and wrist extension; and this seems to be related to the
\end{abstract}

The original version of this article was revised due to a retrospective Open Access order.

Mohammad M. Al-Qattan

moqattan@hotmail.com

1 Department of Surgery, King Saud University, PO Box 18097, Riyadh 11415, Saudi Arabia

2 Department of Obstetrics and Gynecology, King Saud University, Riyadh, Saudi Arabia availability of more cable grafts to reconstruct the posterior division of the upper trunk and the middle trunk.

Level of Evidence: Level III, therapeutic study

Keywords Obstetric brachial plexus $\cdot$ Nerve transfer $\cdot$ Nerve graft

\section{Introduction}

There are several large series describing the results of primary exploration and reconstruction of the brachial plexus in infants with obstetric brachial plexus palsy (OBBP) [1-9]. A recent review by the International Federation of Societies for Surgery of the Hand showed no studies comparing the results of nerve grafting to distal nerve transfer for primary reconstruction of the brachial plexus in infants with OBBP [10]. The committee concluded that surgeons need to avoid an over-reliance on nerve transfers and should be more inclined for nerve graft reconstruction [10].

In extended Erb's palsy (involving the C5, C6, and C7 roots) with double root avulsion, only one root is available for intraplexus neurotization. Distal nerve transfers for biceps reconstruction in OBBP were first introduced by Al-Qattan in 2002 who described the use of Oberlin nerve transfer (ulnar nerve fascicle transfer to the biceps nerve) in two cases of OBBP [11]. Our obstetric brachial plexus clinic was established in 1995, and we started using distal nerve transfers for elbow flexion in primary reconstruction of OBBP in 2002. This gave us the opportunity to compare two primary surgical reconstructive strategies in infants with extended Erb's palsy and double root avulsion: reconstruction of elbow flexion by intraplexus neurotization in one group and by distal nerve transfer in the other group. This paper is a retrospective comparative study of these two groups of patients. 


\section{Patients and methods}

Ethical approval was obtained for this retrospective study. The study included all infants (seen between 1995 and 2013) with extended Erb's obstetric palsy and double root avulsion; and who were treated surgically by primary reconstruction of the brachial plexus before 6 months of age. Patients who were operated upon after 6 months of age and those who had a follow-up of less than 3 years were not included. It should be noted that the definition of root avulsion in the current paper is "complete" avulsion of the root; and this was confirmed by the presence of an "empty" foramen as well as the presence of a visible bulge of the dorsal root ganglion in the avulsed root. Infants with partial avulsion (a lesion classified by Terzis [1] as avulsion-rupture injury) and infants with avulsion in situ (defined by Al-Qattan [12] as a pale root which is still attached to the foramen, but with zero response to electric stimulation) were not included in the study.

The study population was divided into two groups. In group I, primary reconstruction was done by spinal accessory to suprascapular nerve transfer and by intraplexus neurotization of the upper and middle trunks using the available (one) root of the brachial plexus. In group II, primary reconstruction was done by spinal accessory to suprascapular nerve transfer, transfer of a fascicle from either the ulnar or median nerve to the biceps nerve, and intraplexus neurotization of the posterior division of the upper and middle trunks using the available (one) root of the brachial plexus.
In our center, routine motor assessment of relevant functions is done according to the scores shown in Table 1; and the table also defines what is considered as a "satisfactory" functional outcome. We generally do not offer secondary procedures (such as tendon transfers, osteotomies) for patients who reach these satisfactory scores.

Our patient population included many referrals from the entire country. Compliance with postoperative physiotherapy is usually much better during the first 3 years after surgery. Later on, many cases stop physiotherapy; inviting the development of secondary contractures. Hence, we felt that assessment of a satisfactory outcome at the final follow-up in the current comparative study is not appropriate because group I was done before 2002 and group II after 2002. Hence, group I tended to have longer follow-up time and this would bias the results. Therefore, we decided to document the results in both groups at the 3-year follow-up point only; which is also the minimum follow-up required to be included in the study.

The following data were collected at 3 years postoperatively: the number of patients in each group, timing of surgery, intraoperative findings, method of primary reconstruction of the brachial plexus, motor assessment, and percentage of a satisfactory outcome at each relevant motor function. The percentage of satisfactory outcomes was compared between the two groups using the Chi-Square or Fisher's exact tests. A $P$ value less than 0.05 was considered significant.

Table 1 Postoperative motor assessment in children who underwent primary brachial plexus reconstruction

\begin{tabular}{|c|c|c|}
\hline Function & Scoring or measurement of function & $\begin{array}{l}\text { Definition of a satisfactory } \\
\text { functional outcome }\end{array}$ \\
\hline Shoulder abduction & Measured as degrees of shoulder abduction & Abduction $120^{\circ}$ or more \\
\hline Shoulder external rotation & $\begin{array}{l}1=\text { The hand reaches the abdomen or thorax; } 2=\text { The hand reaches the mouth; } \\
3=\text { The hand reaches the ear; } 4=\text { The hand reaches the occiput; } 5=\text { normal } \\
\text { external rotation }\end{array}$ & A score of 3 or more \\
\hline Elbow flexion and extension & $\begin{array}{l}0=\text { no motion, } 1=\text { active motion with gravity eliminated, } 2=\text { active motion against } \\
\text { gravity, } 3=\text { active motion against resistance reaching } \leq 1 / 2 \text { normal range, } 4=\text { active } \\
\text { motion against resistance reaching }>1 / 2 \text { normal range, } \\
5=\text { normal }\end{array}$ & A score of 4 or 5 \\
\hline $\begin{array}{l}\text { Forearm pronation } \\
\text { and supination }\end{array}$ & $\begin{array}{l}1=\text { over-pronated forearm causing a functional or cosmetic disability } \\
2=\text { over-supinated forearm causing a functional or cosmetic disability } \\
3=\text { functional forearm position (mid pronation - supination or slight pronation) } \\
\text { with no or minimal active motion } \\
4=\text { same as } 3 \text { but with good (over } 20^{\circ} \text { ) active pronation/supination } \\
5=\text { normal range of motion }\end{array}$ & A score of 3 or more \\
\hline Wrist extension & $\begin{array}{l}0=\text { non-functional (no active extension or extension only with gravity eliminated) } \\
1=\text { active wrist extension against gravity to less than neutral } \\
2=\text { active wrist extension against gravity to neutral or more than neutral } \\
3=\text { normal wrist extension }\end{array}$ & A score of 2 or 3 \\
\hline Digital extension & $\begin{array}{l}0=\text { non-functional (no active extension or extension only with gravity eliminated) } \\
1=\text { active digital extension against gravity to less than } 1 / 2 \text { range of motion } \\
2=\text { active digital extension against gravity to more than } 1 / 2 \text { range of motion } \\
3=\text { normal digital extension }\end{array}$ & A score of 2 or 3 \\
\hline
\end{tabular}

Note that wrist flexion and hand function are not included in the assessment because C8-T1 roots are not affected in extended Erb's palsy 
Table 2 Distribution of root rupture and avulsion in the two study groups

\begin{tabular}{lll}
\hline Root & Group I $(n=29)$ & Group II $(n=26)$ \\
\hline C5 & 26 ruptured, 3 avulsed & 24 ruptured, 2 avulsed \\
C6 & 2 ruptured, 27 avulsed & 1 ruptured, 25 avulsed \\
C7 & 1 ruptured, 28 avulsed & 1 ruptured, 25 avulsed \\
\hline
\end{tabular}

\section{Results}

Group I included 29 patients with unilateral extended Erb's palsy and double root avulsion; and the timing of surgery ranged from 4 to 6 months (mean of 5.2 months). Group II included 26 patients with unilateral extended Erb's palsy and double root avulsion; and the timing of surgery ranged from 4 to 6 months (mean 5.3 months). Intraoperative findings were similar in both groups with the majority showing $\mathrm{C} 5$ root rupture and avulsion of the $\mathrm{C} 6$ and 7 roots (Table 2). The method of reconstruction is shown in Table 3. In both groups, shoulder external rotation was reconstructed by spinal accessory to suprascapular nerve transfer. The main difference between the two groups is the method of elbow flexion reconstruction. In group I, three cable grafts were connected from the single ruptured root to the anterior division of the upper trunk for elbow flexion reconstruction. In group II, elbow flexion reconstruction was done by a distal nerve transfer either from the ulnar or median nerve. This provided more cable grafts for reconstruction of the posterior division of the upper trunk and the middle trunk in group II when compared to group I as shown in Table 3.

Table 4 shows the results for should abduction at 3 years. Shoulder abduction ranged from $30^{\circ}$ to $100^{\circ}$ (mean of $60^{\circ}$ ) in group I; and the percentage of a satisfactory outcome was $0 \%$. In contrast, shoulder abduction ranged from $50^{\circ}$ to $180^{\circ}$ (mean $109^{\circ}$ ) in group II, and $42.3 \%$ of patients qualified for a satisfactory outcome. The outcome was significantly better in group II $(P<0.0001$ by the Chi-Square test).
For external rotation of the shoulder (Table 5), the percentage of a satisfactory outcome (a score of 3 or more) was higher in group II $(57.7 \%)$ than that in group I $(48.3 \%)$; but the difference did not reach statistical significance $(P=0.485$ by the Chi-Square test).

Except for one patient in each group, all patients in both groups obtained a satisfactory elbow flexion score (Table 6). A score of 4 or 5 was obtained in $96.6 \%$ of group I patients and in $96.2 \%$ of group II patients; and the difference between the two groups was not significant $(P=0.727$ by Fisher's exact test). Similarly, all patients in both groups qualified for a score of 4 of elbow extension (100\% satisfactory outcome). The reason behind not having full elbow extension was a mild elbow flexion contracture $\left(10^{\circ}-30^{\circ}\right)$ which was noted in all patients in both groups. Forearm pronation/supination was also satisfactory in all patients in both groups (Table 7). No statistical testing was done for elbow extension or forearm rotation because the outcome was satisfactory in all patients in both groups for these two functions.

Wrist extension scores are shown in Table 8. Nine patients $(31.0 \%)$ in group I and 20 patients (76.9\%) in group II obtained a satisfactory outcome and the difference was significant ( $P=0.001$ by the Chi-Square test). Digital extension scores are shown in Table 9. Twenty-five patients $(86.2 \%)$ in group I and 25 patients $(96.2 \%)$ in group II obtained a satisfactory outcome and the difference between the two groups was not significant ( $P=0.212$ by Fisher's exact test).

\section{Discussion}

The use of the spinal accessory to suprascapular nerve transfer is a well-established procedure for several decades [13-15]; and is usually done in brachial plexus injuries with root avulsion. When there is no root avulsion, the suprascapular nerve is usually neurotized using the $\mathrm{C} 5$ root. There are two studies

Table 3 The method of primary reconstruction of the brachial plexus in the two study groups

\begin{tabular}{|c|c|c|}
\hline $\begin{array}{l}\text { Motor function to be } \\
\text { reconstructed }\end{array}$ & Group II & Group II \\
\hline \multicolumn{3}{|l|}{ C5 root function } \\
\hline $\begin{array}{l}\text { - Shoulder abduction (the posterior } \\
\text { division of the upper trunk) } \\
\text { - Shoulder external rotation } \\
\text { (suprascapular nerve) }\end{array}$ & $\begin{array}{l}\text { One cable graft from the ruptured root to } \\
\text { the posterior division of the upper trunk } \\
\text { Spinal accessory to suprascapular nerve } \\
\text { transfer }\end{array}$ & $\begin{array}{l}\text { Two or three cable grafts from the ruptured } \\
\text { root to the posterior division of the upper trunk } \\
\text { Spinal accessory to suprascapular nerve transfer }\end{array}$ \\
\hline \multicolumn{3}{|l|}{ C6 root function } \\
\hline $\begin{array}{l}\text { - Elbow flexion (the anterior divison } \\
\text { of the upper trunk) }\end{array}$ & $\begin{array}{l}\text { Three cable grafts from the ruptured } \\
\text { root to the anterior division of } \\
\text { the upper trunk }\end{array}$ & $\begin{array}{l}\text { Distal nerve transfer (one fascicle from } \\
\text { the ulnar or median nerve to the } \\
\text { biceps nerve) }\end{array}$ \\
\hline \multicolumn{3}{|l|}{ C7 root function } \\
\hline $\begin{array}{l}\text { - Neurotization of the middle trunk for } \\
\text { elbow/wrist/digital extension }\end{array}$ & $\begin{array}{l}\text { One cable graft from the ruptured } \\
\text { root to the middle trunk }\end{array}$ & $\begin{array}{l}\text { Two or three cable grafts from the } \\
\text { ruptured root to the middle trunk }\end{array}$ \\
\hline
\end{tabular}


Table 4 Shoulder abduction at 3 years in the two study groups

\begin{tabular}{lll}
\hline $\begin{array}{l}\text { Active shoulder } \\
\text { abduction in degrees }\end{array}$ & $\begin{array}{l}\text { Group I } \\
(n=29)\end{array}$ & $\begin{array}{l}\text { Group II } \\
(n=26)\end{array}$ \\
\hline Less than $30^{\circ}$ & 0 & 0 \\
$30^{\circ}$ & 2 & 0 \\
$40^{\circ}$ & 6 & 0 \\
$50^{\circ}$ & 5 & 2 \\
$60^{\circ}$ & 7 & 1 \\
$70^{\circ}$ & 2 & 3 \\
$80^{\circ}$ & 3 & 1 \\
$90^{\circ}$ & 2 & 4 \\
$100^{\circ}$ & 2 & 2 \\
$110^{\circ}$ & 0 & 2 \\
$120^{\circ}$ & 0 & 2 \\
$130^{\circ}$ & 0 & 3 \\
$140^{\circ}$ & 0 & 1 \\
$150^{\circ}$ & 0 & 1 \\
$160^{\circ}$ & 0 & 0 \\
$179^{\circ}$ & 0 & 3 \\
$180^{\circ}$ & 0 & 1 \\
\hline
\end{tabular}

in the literature comparing suprascapular nerve reconstruction in OBBP with either nerve grafting from $\mathrm{C} 5$ or the spinal accessory nerve transfer $[16,17]$. The outcome of both methods was similar in both studies $[16,17]$. In the current study, the spinal accessory transfer was used in all patients because of the presence of root avulsion. The outcome of external rotation was similar in both groups: about $50 \%$ could reach the ear or the back of the head. It is important to note that children with this satisfactory functional outcome utilize the help of shoulder abduction to reach the head. Hence, this satisfactory outcome is not a measure of true external rotation of the shoulder as demonstrated by Pondaag et al. [17]. It is also important to note that we do not use the Mallet score to assess the shoulder in OBBP because we noted that several children will have a discrepancy between the deficiency in shoulder abduction and shoulder external rotation. Hence, we document the outcome of these two shoulder functions separately as recommended by Al-Qattan and El-Sayed [18].

Table 5 Shoulder external rotation at 3 years in the two study groups

\begin{tabular}{llc}
\hline Shoulder external rotation score $^{\mathrm{a}}$ & Group I $(n=29)$ & Group II $(n=26)$ \\
\hline 1 & 7 & 3 \\
2 & 8 & 8 \\
3 & 7 & 4 \\
4 & 7 & 11 \\
5 & 0 & 0 \\
\hline
\end{tabular}

${ }^{\mathrm{a}}$ The score as per Table 1
Table 6 Elbow flexion at 3 years in the two study groups

\begin{tabular}{lcc}
\hline Elbow flexion score $^{\mathrm{a}}$ & Group I $(n=29)$ & Group II $(n=26)$ \\
\hline 0 & 0 & 1 \\
1 & 0 & 0 \\
2 & 0 & 0 \\
3 & 1 & 0 \\
4 & 4 & 2 \\
5 & 24 & 23 \\
\hline
\end{tabular}

${ }^{\mathrm{a}}$ The score as per Table 1

In adult traumatic brachial plexus injuries, isolated $\mathrm{C} 5$ and C6 avulsion is a common injury. In these cases, elbow flexion reconstruction is usually done using distal nerve transfers utilizing a single fascicle from the ulnar nerve to the biceps nerve (which was first reported in adults by Oberlin et al. in 1994) [19], a single fascicle from the median nerve to the biceps nerve, or double fascicular transfer (one fascicle from the ulnar nerve and another from the median nerve) to re-innervate the biceps and brachialis muscles [20]. In OBBP, the first use of distal nerve transfer for biceps reconstruction was in 2002 [11] and this was followed by several series utilizing the ulnar nerve, median nerve, or both in the double fascicular transfer [21-26]. The results in infants have been excellent, and this has been observed in the current series.

In adults, Oberlin nerve transfer gives better results in cases of C5-C6 avulsion when compared to those with C5-C6-C7 avulsion [27, 28]. Our study shows that biceps distal nerve transfer in OBBP gives excellent results even in the presence of $\mathrm{C} 7$ avulsion; which was present in the majority of cases in both groups (Table 2).

The most unique feature of the current study is the comparison between two reconstructive strategies in infants with extended Erb's palsy and double root avulsion. Both groups were operated upon by the same surgeon and both had similar operative findings. In the first group, elbow flexion reconstruction was done by nerve grafting from the available ruptured root to the anterior division of the upper trunk. In cases of extended Erb's palsy with double root avulsion, it is expected that the surgeon will give the priority to elbow flexion and

Table 7 Forearm pronation/supination at 3 years in the two study groups

\begin{tabular}{lcc}
\hline $\begin{array}{l}\text { Forearm pronation/ } \\
\text { supination score }^{\mathrm{a}}\end{array}$ & Group II $(n=29)$ & Group II $(n=26)$ \\
\hline 1 & 0 & 0 \\
2 & 0 & 0 \\
3 & 23 & 22 \\
4 & 6 & 4 \\
5 & 0 & 0 \\
\hline
\end{tabular}

${ }^{\mathrm{a}}$ The score as per Table 1 
Table 8 Wrist extension at 3 years in the two study groups

\begin{tabular}{lcc}
\hline Wrist extension score $^{\mathrm{a}}$ & Group I $(n=29)$ & Group II $(n=26)$ \\
\hline 0 & 5 & 3 \\
1 & 15 & 3 \\
2 & 9 & 15 \\
3 & 0 & 5 \\
\hline
\end{tabular}

${ }^{\mathrm{a}}$ The score as per Table 1

not to shoulder abduction or wrist extension. Hence, most of the cable grafts were utilized for elbow flexion at the expense of shoulder abduction and wrist extension. In the second group, the use of a distal nerve transfer for elbow reconstruction provided more cable grafts for shoulder abduction and wrist extension reconstruction. Hence, it is of no surprise that the outcome of shoulder abduction and wrist extension was significantly better in the second group.

The excellent recovery of elbow extension and digital extension in both groups is probably attributed to the fact that the triceps and digital extensors are supplied by both the $\mathrm{C} 7$ and $\mathrm{C} 8$ roots; and the latter root is intact in both study groups.

All patients in both groups had avulsion of two roots and rupture of the third root. Hence, a single root was used for neurotization. The average number of nerve fibers in the $\mathrm{C} 5$ root (16,472 fibers) is much lower than the number in the C6 (27,421 fibers) and the C7 (23,781 fibers) roots [2]. In our series, the root used for neurotization was the $\mathrm{C} 5$ root in the majority of cases in both groups (see Table 2). Therefore, the available number of fibers was similar in the two study groups.

Theoretically, group II had an advantage over group I with regard to the risk of postoperative co-contraction of elbow flexors and extensors. In group II, the biceps was neurotized separately by a distal nerve transfer; and hence, there was no risk of co-contraction. In contrast, group I had neurotization of both elbow flexors and extensors from the same root, hence the risk of co-contraction. We did not specifically assess cocontraction in our series; but a satisfactory elbow flexion was seen in 28 out of 29 patients in group I indicating the cocontraction was not a major concern.

In conclusion, the use of distal nerve transfer for biceps reconstruction in extended Erb's obstetric palsy with double

Table 9 Digital extension at 3 years in the two study groups

\begin{tabular}{lcc}
\hline Digital extension score $^{\mathrm{a}}$ & Group I $(n=29)$ & Group II $(n=26)$ \\
\hline 0 & 0 & 0 \\
1 & 4 & 1 \\
2 & 10 & 6 \\
3 & 15 & 19 \\
\hline
\end{tabular}

${ }^{\mathrm{a}}$ The score as per Table 1 root avulsion gives a better outcome for shoulder abduction and wrist extension; and this seems to be related to the availability of more cable grafts to the posterior division of the upper trunk and to the middle trunk.

\section{Compliance with ethical standards}

Conflict of interest Mohammad M. Al-Qattan and Amel Ahmed F. ElSayed declare that they have no conflict of interest.

Patient consent The parents of all patients gave consent for inclusion in the study.

Funding The study is funded by the College of Medicine Research Center, Deanship of Scientific Research, King Saud University, Riyadh, Saudi Arabia.

Ethical approval The study was performed in accordance with the ethical standards of the 1964 Declaration of Helsinki and its later amendments. Written ethical committee approval was obtained from the research committee at Riyadh National (CARE) hospital, Riyadh, Saudi Arabia. All our OBBP patients give consent for treatment and the use of their data in education and research. No further formal consent was required because the study protocol included retrospective, epidemiologic evaluation of anonymous and routine patient data, and procedural and outcome parameters.

Open Access This article is distributed under the terms of the Creative Commons Attribution 4.0 International License (http:// creativecommons.org/licenses/by/4.0/), which permits use, duplication, adaptation, distribution and reproduction in any medium or format, as long as you give appropriate credit to the original author(s) and the source, provide a link to the Creative Commons license and indicate if changes were made.

\section{References}

1. Terzis JK, Kokkalis ZT (2009) Elbow flexion after primary reconstruction in obstetric brachial plexus palsy. J Hand Surg Eur 34: 449-458

2. Gilbert A, Pivato G, Kheiralla T (2006) Long-term results of primary repair of brachial plexus lesions in children. Microsurgery 26: 334-342

3. Borschel GH, Clarke HM (2009) Obstetrical brachial plexus palsy. Plast Reconstr Surg 124(Supplement):144e-155e

4. Waters PM (1999) Comparison of the natural history, the outcome of microsurgical repair, and the outcome of operative reconstruction in brachial plexus birth palsy. J Bone Joint Surg Am 81:649-659

5. Malessy MJA, Pondaag W (2011) Nerve surgery for neonatal brachial plexus palsy. J Pediatr Rehabil Med 4:141-148

6. Hentz VR, Meyer RD (1991) Brachial plexus microsurgery in children. Microsurgery 12:175-185

7. Clarke HM, Al-Qattan MM, Curtis CG, Zuker RM (1996) Obstetrical brachial plexus palsy: results following neurolysis of conducting neuromas-in-continuity. Plast Reconstr Surg 97:974982

8. Birch R, Ahad N, Kono H, Smith S (2005) Repair of obstetric brachial plexus palsy. Results in 100 children. J Bone Joint Surg Br 87:1089-1095 
9. Lin JC, Schwentker-Colizza A, Curtis CG, Clarke HM (2009) Final results of grafting versus neurolysis in obstetrical brachial plexus palsy. Plast Reconstr Surg 123:939-948

10. Tse R, Kozin SH, Malessy MJ, Clarke HM (2015) International Federation of Societies for Surgery of Hand Committee report: the role of nerve transfers in the treatment of neonatal brachial plexus palsy. J Hand Surg Am. 40:1246-1259

11. Al-Qattan MM (2002) Oberlin's ulnar nerve transfer to the biceps nerve in Erb's birth palsy. Plast Reconstr Surg 109:405-407

12. Al-Qattan MM (2003) Obstetric brachial plexus palsy associated with breech delivery. Ann Plast Surg 51:257-264

13. Tuttle H (1913) Exposure of the brachial plexus with nerve transplantation. JAMA 61:15-17

14. Narakas AO (1987) Neurotization or nerve transfer in traumatic brachial plexus lesions. In: Tubiana R (ed): The Hand. Philadelphia: WB Saunders. 3:656

15. Kawabata H, Kawai H, Masatani T, Yasui N (1994) Accessory nerve neurotization in infants with brachial plexus birth palsy. Microsurgery 15:768-772

16. Tse R, Marcus JR, Curtis CG, Dupuis A, Clarke HM (2011) Suprascapular nerve reconstruction in obstetrical brachial plexus palsy: spinal accessory nerve transfer versus C5 root grafting. Plast Reconstr Surg 127:2391-2396

17. Pondaag W, de Boer R, Van Wijlen-Hempel MS et al (2005) External rotation as a result of suprascapular nerve neurotization in obstetric brachial plexus lesions. Neurosurgery 57:530-537

18. Al-Qattan MM, El-Sayed AA (2014) Obstetric brachial plexus palsy: the Mallet grading system for shoulder function-revisited. Biomed Res Int 2014:398121

19. Oberlin C, Beal D, Leechavengvongs $S$ et al (1994) Nerve transfer to biceps muscle using a part of ulnar nerve for C5-C6 avulsion of the brachial plexus: anatomical study and report of four cases. J Hand Surg Am. 19:232-237

20. Mackinnon SE, Nevak CB, Myckatyn TM, Jung TH (2005) Results of re-innervation of the biceps and brachialis muscles with a double fascicular transfer for elbow flexion. J Hand Surg Am 30:978-985

21. Little KJ, Zlotolow DA, Soldado F, Cornwell R, Kozin SH (2014) Early functional recovery of elbow flexion and supination following median and/or ulnar nerve fascicle transfer in upper neonatal brachial plexus palsy. J Bone Joint Surg Am 96:215-221

22. Ladak A, Morhart M, O'Grady K et al (2013) Distal nerve transfers are effective in treating patients with upper trunk obstetrical brachial plexus injuries. Plast Reconstr Surg 132:985e-992e

23. Estrella EP, Mella PM (2013) Double nerve transfer for elbow flexion in obstetric brachial plexus injury: a case report. J Plast Reconst Aesthet Surg 66:423-426

24. Al-Qattan MM, Al-Kharfy TM (2014) Median nerve to biceps nerve transfer to restore elbow flexion in obstetric brachial plexus palsy. Biomed Res Int 2014:854084

25. Siqueira MG, Socolovsky H, Heise CO, Martins RS, Di Masi G (2012) Efficacy and safety of Oberlin's procedure in the treatment of brachial plexus birth palsy. Neurosurgery 71:1156-1161

26. Ghanghurde BA, Mehta R, Ladkat KM, Raut BB, Thatte MR (2016) Distal transfers as a primary treatment in obstetric brachial plexus palsy: a series of 20 cases. J Hand Surg Eur 41:875-881

27. Loy S, Bhatia A, Asfazadourian H, Oberlin C (1997) Ulnar nerve fascicle transfer onto to the biceps muscle nerve in C5-C6 or C5C6-C7 avulsions of the brachial plexus. Eighteen cases. Ann Chir Main Memb Super 16:275-284

28. Sungpet A, Suphachatwong C, Kawinwonggowit V, Patradul A (2000) Transfer of a single fascicle from the ulnar nerve to the biceps muscle after avulsions of upper roots of the brachial plexus. J Hand Surg Br 25:325-328 